\title{
California Papaya Fruit Maturity Classification Uses Learning Vector Quantization
}

\author{
*Romi Wiryadinata \\ Department of Electrical Engineering, \\ University of Sultan Ageng Tirtayasa, \\ Indonesia Center of Execelenc for \\ Food Security (I-CEFORY), \\ UNTIRTA (Local Food \\ Innovation) \\ Jl. Jend. Sudirman km 3, Kota Cilegon \\ Banten, Indonesia 42435 \\ *wiryadinata@untirta.ac.id \\ Andy A. Fatmawaty \\ Department of Agriculture, \\ University of Sultan Ageng Tirtayasa \\ Jl. Jend. Sudirman km 3, Kota Cilegon \\ Banten, Indonesia 42435 \\ aafatmawaty@yahoo.com
}

\author{
Muhammad Saepudin \\ Department of Electrical Engineering, \\ University of Sultan Ageng Tirtayasa \\ Jl. Jend. Sudirman km 3, Kota Cilegon \\ Banten, Indonesia 42435 \\ muhammadsaepudin94@gmail.com
}

Alimuddin

Department of Electrical Engineering, University of Sultan Ageng Tirtayasa, Indonesia Center of Execelenc for Food Security (I-CEFORY),

UNTIRTA (Local Food Innovation)

Jl. Jend. Sudirman km 3, Kota Cilegon Banten, Indonesia 42435 alimuddin@untirta.ac.id

\author{
Oktavia Widia Ningrum \\ Department of Electrical Engineering, \\ University of Sultan Ageng Tirtayasa \\ Jl. Jend. Sudirman km 3, Kota Cilegon \\ Banten, Indonesia 42435 \\ oktaviawidia97@gmail.com
}

Imamul Muttakin

Department of Electrical Engineering, University of Sultan Ageng Tirtayasa

J1. Jend. Sudirman km 3, Kota Cilegon Banten, Indonesia 42435 imamul@untirta.ac.id

\begin{abstract}
This research aims to build a system for the classification of papaya maturity level using Learning Vector Quantization. The classification process is done by the colour feature extraction value. Forty-five images consist of 30 images for training data and $\mathbf{1 5}$ images for test data were used. The images were divided into 3 classes: rip, mature and raw. The parameters for classification are mean, skewness, and kurtosis. Test results 1 obtained an accuracy of $60 \%$ consisting of 9 true images and 6 incorrect images with hidden layer 5 and learning rate 0,1 . Test results 2 obtained an accuracy of $66,67 \%$ consisting of 10 true images and 5 incorrect images with hidden layer 10 and learning rate 0,5 . Test image data are 15 papaya images consisting of 5 mature images, 5 imperfect images, and 5 raw images.
\end{abstract}

Keywords: Classification of maturity, Papaya California, Learning Vector Quantization

\section{INTRODUCTION}

Papaya is one of tropical fruit that has high economic value, a potential source of income, and an important role in food security (availability). As an all years round fruit, papaya production in Indonesia for the last three years tend to be stable around 906305 tons (2012), 909818 tons (2013), and 840112 tons (2014). Papaya fruit can be consumed in a fresh or other processed forms such as candies and pickles.

Postharvest agriculture includes two things: process technology and machine tool technology. One of the postharvest problems in papaya fruit produced at a large scale or industrial is in the sorting of papaya fruit. During this stage, farmers identify the maturity level of papaya fruit using a visual skin colour analysis of human eyes. This identification process has several disadvantages such as differences in perception, time-consuming, labouredly, and it is subjective.

There is a necessity for a method that can guarantee the maturity level of papaya. Nowadays, research on image processing technique becomes a trend, especially for the determination of good quality fruit condition, weight and size.

In previous research, the introduction of the maturity level of Rabo papaya fruit using colour image processing (RGB) with K-means clustering was done with 30 pieces of images. The results obtained from the study were $60 \%$ identified as half matured, $90 \%$ identified as nearly mature, and $100 \%$ recognizable mature [1]. Papaya's research was based on image analysis using thresholding and morphology method and classification based on volume and weight of papaya with $90 \%$ accuracy [2].

Papaya maturity classification was studied on (Carica papaya 1) California (callina-ipb 9) in HSV colour space and k-nearest neighbours algorithm using data of 31 images consist of 19 reference images and 12 test images. The level of accuracy obtained was $75 \%$ for the neighbouring $\mathrm{K} 3$. Testing with $\mathrm{K}$ neighbouring 5 received an accuracy of $83.34 \%$ [3].

Another research identified the degree of ageing and maturity of papaya (Carica papaya 1.) Ipb 1 by processing digital images and artificial neural networks using RGB colour features, HSI, and GLCM features of energy, contrast, and homogeneity as inputs. These features were used as a reference in determining the age and fruit maturity. The 
results obtained were $97.8 \%$ for papaya maturity and $100 \%$ for papaya ageing [4]. Afterwards, for storage it is optimized using the genetic algorithm [5].

Furthermore, the analysis of colour content level analysis for the determination of maturity level on the image of papaya callina fruit used 300 images with the composition of each 100 images for raw, mature, and fully ripe. Based on the research it can be concluded that the content of the colour values of the data obtained is following the actual conditions when using the eye as a sensor determining the fruit maturity level [6].

Research that has used digital image processing has also been carried out such as for determining the maturity of tomato [7], cherry dan strawbery [8], persimon [9], banana [10], durian [11], and papaya [12].

This research implements the image processing in the classification of papaya fruit maturity based on RGB colour feature which will then be processed in learning with Learning Vector Quantization (LVQ).

The data are taken from California papayas from the California papaya plantation in Cilegon city (Pasir Angin, Cikerai, Cibeber).

\section{RESEARCH METHOD}

The method performed to classify the level of papaya California maturity are shown in Figure 1.

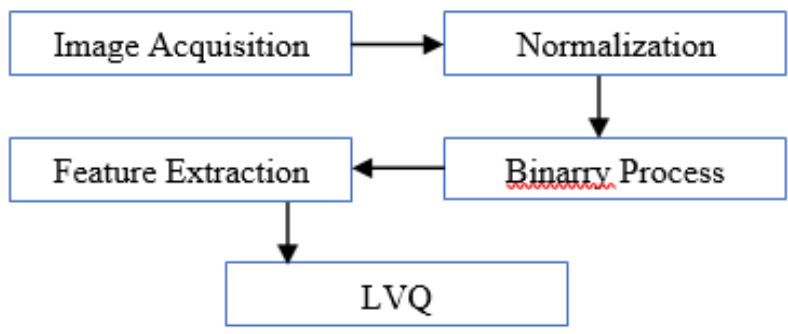

Fig. 1. Block Diagram

\section{A. Image Acquisition}

The image acquisition stage is performed to take papaya image inside the box. The box is designed in such a way as to get a good and clear picture. Design of the trial box can be seen in Figure 2.

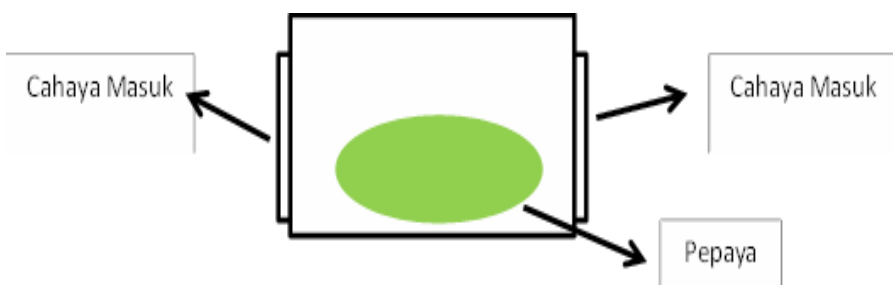

Fig. 2. Trial box design

The trial box is illuminated on right, left and top. The inner side of the box is arranged in such a way that the background image becomes white. The box can be seen in Figure 3 .

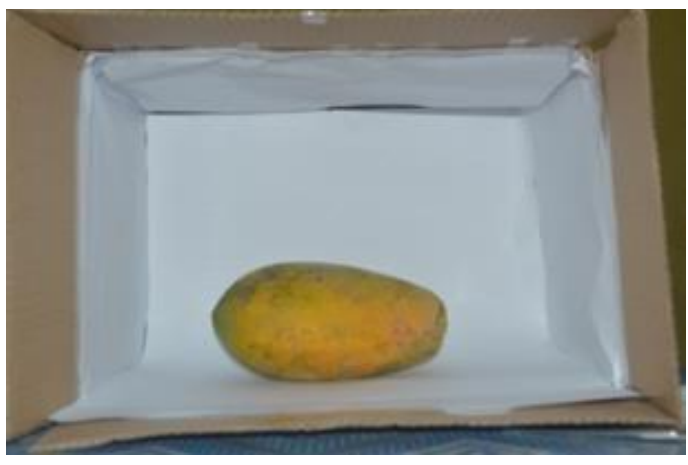

Fig. 3. Trial box

\section{B. Image Normalization}

In this step, the image size is changed to smaller and uniform. Resizing this image is intended to reduce the computer workload so computation time is faster. The original image size is $3008 \times 2000$ pixels. It is then normalized to $445 \times 315$ pixels.

\section{Binary process}

The binary process aimed to recognize the object and background or to separate between objects with the background. In this process, the background colour became black or 0 . It makes objects recognizable without interference from the background.

\section{Feature extraction}

The extraction of colour features in papaya consists of mean, skewness and kurtosis. Mean is the average pixel value (Pij) on each channel R, G and B.

$$
\mu=\frac{1}{M N} \sum_{i=1}^{M} \quad \sum_{j=1}^{N} P i j
$$

$\mathrm{M}$ and $\mathrm{N}$ are the length and width value of the pixels in the image respectively. Skewness and kurtosis are average pixel value (Pij) minus the mean $(\mu)$ while incrementing $n$ on each channel. Skewness is the degree of asymmetry of the distribution. If skewness $=0$ then it said to be symmetrical. Kurtosis is the degree of tilting of distribution (usually measured relative to a normal distribution). In this research, the intended distribution is colour. By calculation, skewness is the third moment on a mean and kurtosis is the fourth moment on a mean.

Therefore, on the formula above, $\mathrm{n}$ has a value of 3 for kurtosis and has a value of 4 for skewness. A histogram is an effective graphical technique to show skewness and kurtosis of a dataset.

\section{E. Design of Learning Vector Quantization}

LVQ is a supervised method of pattern classification. Input vectors will be grouped in the same class. LVQ network is indeed similar to the network that has been developed by Kohonen in 1982 .

This training stage is a step for a network to practice, that is by changing the values. The new problem solving will be done when the training process is completed. That step is phase mapping or testing process. The process steps in this research are described as follows:

a. Determine training data, test data and target data as input on the neural network process. 
b. Before building the network, the normalization process to organize and unify image data is conducted first.

c. Set the training parameters in the form of colour features. Then, the training process is run afterwards.

d. Obtain the output of several variables from the training process such as initial and final weights as well as the bias layers.

e. Conduct testing of the data that participated in training. Hence, error data is obtained as a material consideration of success.

f. Further testing will be performed on data that do not participate in the training process.

This research creates the image database used as training and testing data. It then proceeds with the classification process using LVQ. The results obtained are from the classification of data testing based on training data that are known to each class. The scheme is shown in the block diagram in Figure 4.

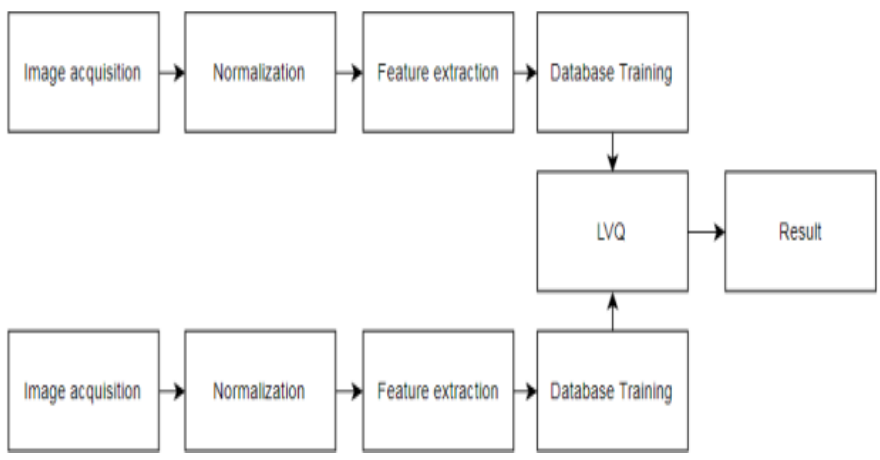

Fig. 4. Diagram Block

\section{RESULT AND DISCUSSION}

\section{A. Input Image}

The images are obtained from the process of collecting data of papaya images from Rapid Farm (Pasir Angin, Cikerai, Cibeber, Cilegon. The image data consist of papaya images of 15 ripe, 15 mature, and 15 raw images. Then the images are divided into 30 images of papaya as training data which consists of papaya in ripe, mature, and raw condition. There are 15 images of papaya as test data. Example of papaya image shown in Figure 5.

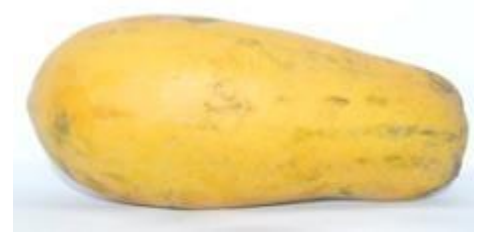

Fig. 5. Image of Papaya

\section{B. Preprocessing Result}

Among preprocessing step is the resizing to modify pixel size. The input image with a size of 3008 x 2000 pixels is converted to 455 x 315 pixels. Next, the image segmentation process to separate the background with the object is conducted. This process performed several steps. First, it separates the image into 3-colour layers (red, green, blue).
Then, it is sharpening the contrast using Contrast Limited Adaptive Histogram Equalization (CLAHE) on each colour layer. To see the results of contrast sharpening, the 3 colour layers are recombined.

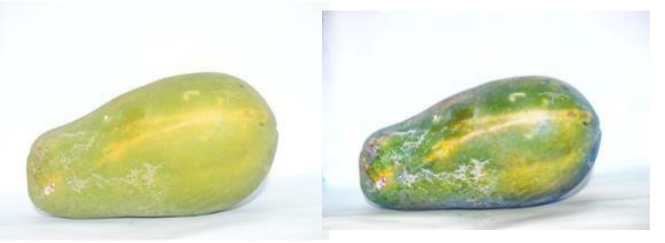

Fig. 6. Preprocessing Result; (a) Real or Input image, (b) Image of Edgesharp Results

From Figure 6, it can be seen that the initial image has undergone contrast sharpening. It is important to separate the background with the image to be segmented. Furthermore, the contrast-sharpened image is then converted to a binary image with the threshold proposed on each colour layer (Red, Green, Blue).

Subsequently, im $2 b w$ converts grayscale image into a binary image with a threshold. The result of this process is that each layer will produce an image with a white background (in binary value 1). Then, the image will be segmented, so the background should have a value of 0 . To do that, the image is inverted.

After that, the three-layer images are combined with the OR operator. The result has small areas that are not covered. In this case, a small area that is not needed can be eliminated by filling the hollow area. Then, an area of less than 40 pixels is removed.

The last step, the image of the above process is changed by replacing the area (Figure 7) with the value 1 to have the colour intensity as the original image. Then, the three layers are combined.

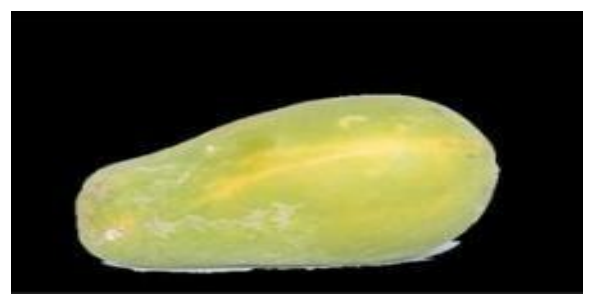

Fig. 7. Image of Segmentation Results

\section{C. $L V Q$ (Learning Vector Quantization) Training}

LVQ is used to classify the maturity level of papaya. LVQ training is done on test data 2. It can be seen in Figure 8.

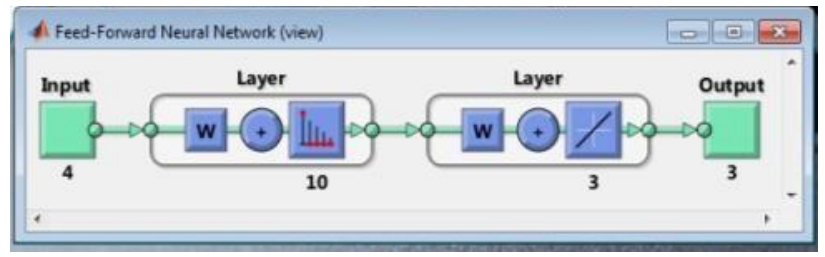

Fig. 8. Neural Network View

Figure 8. shows the neural network view of the image data of papaya. The input data used consists of 3 classes, with the hidden layer of 10 layers. The output is obtained in the form of three classes of maturity of papaya, namely ripe, 
raw, and mature. Neural networks are trained using a setting of epoch 100 iterations and 10 layers of hidden layer. The result is shown in Figure 9.

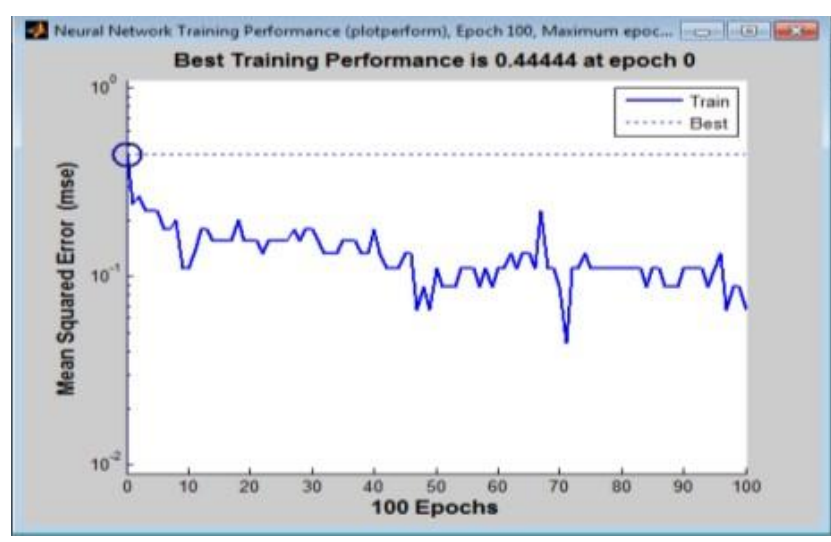

Fig. 9. Graph of Training Performance

Figure 9 is a graph of performance that shows MSE changes to the number of iterations during the training process. On the chart, it can be seen that the value of MSE that has been set as one of the stopping factors of training has been reached.

Figure 9 shows the increasing epoch, as the greater the value of MSE. MSE value decreases with the number of epoch (iteration). So that it is farther away from the true and best value of MSE. The best performance is obtained at epoch 0 with MSE value of 0.44444 . The result is too small than expected, so it needs to improve the set so that results obtained are better and increasing or close to MSE value that has been set. Therefore, the performance of training gets better.

\section{Training data}

Before getting the results of the training, it takes several steps in the process of making neural network structures. Setting the weighting of Training should be arranged in advance using the LVQ algorithm. The input image used in this research is 45 images of papaya. Then, image data are divided into 30 data for training input and 15 data for test input. In training, data has been determined as image class following the image code. The feature extraction used is mean, standard deviation, skewness, and kurtosis is shown in Table 1.

TABLE I. TRAINING DATA

\begin{tabular}{|c|c|c|c|c|c|}
\hline \multirow[b]{2}{*}{ z } & \multirow[b]{2}{*}{ نَّ } & \multicolumn{4}{|c|}{ Feature Extraction } \\
\hline & & 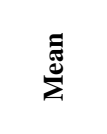 & 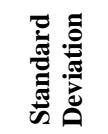 & 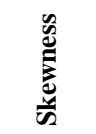 & 商 \\
\hline 1 & Ripe-1 & 80,5451 & 92,5470 & 0,3042 & 1,1321 \\
\hline 2 & Ripe-2 & 70,6358 & 96,9975 & 0,6623 & 1,4622 \\
\hline 3 & Ripe-3 & 67,1787 & 76,0347 & 0,3529 & 1,3073 \\
\hline 4 & Ripe-4 & 97,2826 & 97,2952 & 0,0355 & 1,0536 \\
\hline 5 & Ripe-5 & 73,2099 & 78,1274 & 0,2336 & 1,2278 \\
\hline 6 & Ripe-6 & 71,2453 & 90,3770 & 0,5057 & 1,2884 \\
\hline 7 & Ripe-7 & 72,7759 & 75,4101 & 0,1822 & 1,2252 \\
\hline 8 & Ripe-8 & 73,0062 & 77,2674 & 0,2221 & 1,2437 \\
\hline 9 & Ripe-9 & 75,4928 & 78,4214 & 0,1839 & 1,2247 \\
\hline 10 & Ripe-10 & 64,1205 & 71,2119 & 0,3666 & 1,4055 \\
\hline 11 & Mature-1 & 67,5552 & 91,3138 & 0,6412 & 1,4572 \\
\hline 12 & Mature-2 & 66,6462 & 89,9242 & 0,6337 & 1,4443 \\
\hline 13 & Mature-3 & 79,7435 & 84,6862 & 0,1495 & 1,0675 \\
\hline
\end{tabular}

\begin{tabular}{|l|c|c|c|c|c|}
\hline 14 & Mature-4 & 57,7061 & 88,6066 & 0,9207 & 1,8807 \\
\hline 15 & Mature-5 & 59,3997 & 61,1172 & 0,2367 & 1,3732 \\
\hline 16 & Mature-6 & 80,4965 & 80,2469 & 0,0487 & 1,0949 \\
\hline 17 & Mature-7 & 80,0324 & 91,1106 & 0,2843 & 1,1178 \\
\hline 18 & Mature-8 & 66,9132 & 61,9627 & 0,0517 & 1,3614 \\
\hline 19 & Mature-9 & 59,8948 & 62,0814 & 0,3311 & 1,5498 \\
\hline 20 & Mature-10 & 41,1690 & 65,1080 & 1,0040 & 2,0579 \\
\hline 21 & Raw-1 & 53,5294 & 65,7510 & 0,6859 & 1,9087 \\
\hline 22 & Raw-2 & 37,8196 & 41,9980 & 0,6844 & 2,3117 \\
\hline 23 & Raw-3 & 35,4592 & 46,2353 & 0,9773 & 2,7825 \\
\hline 24 & Raw-4 & 41,4719 & 44,2046 & 0,5681 & 2,0926 \\
\hline 25 & Raw-5 & 38,6188 & 45,2375 & 0,7352 & 2,3260 \\
\hline 26 & Raw-6 & 36,5108 & 46,2901 & 0,9629 & 2,8038 \\
\hline 27 & Raw-7 & 47,2687 & 55,9050 & 0,6354 & 1,8778 \\
\hline 28 & Raw-8 & 43,4947 & 44,4078 & 0,4845 & 2,0691 \\
\hline 29 & Raw-9 & 41,2707 & 43,3293 & 0,5691 & 2,1030 \\
\hline 30 & Raw-10 & 30,1581 & 42,7331 & 1,0774 & 2,7640 \\
\hline
\end{tabular}

\section{E. Test Result}

The data tested are 15 images consisting of ripe, mature and raw with 5 images of each class. Test data can be seen in Table 2.

TABLE II. TEST RESUlT

\begin{tabular}{|c|c|c|c|c|c|}
\hline \multirow[b]{2}{*}{$\stackrel{0}{Z}$} & \multirow[b]{2}{*}{ نُ } & \multicolumn{4}{|c|}{ Feature Extraction } \\
\hline & & 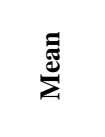 & 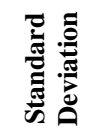 & $\frac{\mathscr{d}}{\dot{d}}$ & 里 \\
\hline 1 & Ripe-11 & 80,9938 & 83,7693 & 0,1559 & 1,1647 \\
\hline 2 & Ripe-12 & 60,3412 & 81,9560 & 0,6616 & 1,4731 \\
\hline 3 & Ripe-13 & 84,1366 & 94,0755 & 0,2442 & 1,0855 \\
\hline 4 & Ripe-14 & 44,2013 & 82,4035 & 1,3591 & 2,8810 \\
\hline 5 & Ripe-15 & 69,5205 & 82,8705 & 0,4299 & 1,3098 \\
\hline 6 & Mature-11 & 71,9834 & 78,4918 & 0,1993 & 1,0760 \\
\hline 7 & Mature-12 & 43,5889 & 55,7706 & 0,7305 & 1,9139 \\
\hline 8 & Mature-13 & 63,6639 & 63,5537 & 0,2209 & 1,4062 \\
\hline 9 & Mature-14 & 69,4014 & 79,8378 & 0,3297 & 1,1842 \\
\hline 10 & Mature-15 & 47,7732 & 59,9030 & 0,7330 & 2,0185 \\
\hline 11 & Raw-11 & 52,0892 & 50,0338 & 0,2939 & 1,6529 \\
\hline 12 & Raw-12 & 37,6704 & 55,5404 & 1,1878 & 2,9626 \\
\hline 13 & Raw-13 & 37,2839 & 53,2268 & 1,1686 & 3,0301 \\
\hline 14 & Raw-14 & 34,4835 & 45,6978 & 0,9692 & 2,7144 \\
\hline 15 & Raw-15 & 42,9629 & 44,8699 & 0,5508 & 2,0633 \\
\hline
\end{tabular}

\section{F. Testing 1}

Testing 1 (Table 3) changes the value of the learning rate from 0.1 to 0.5 , but the hidden layer is not changed: hidden layer 5 and epoch 100.

TABLE III. TESTING 1

\begin{tabular}{|c|c|c|c|c|c|c|c|c|c|c|}
\hline \multirow{2}{*}{ Z } & \multirow{2}{*}{ 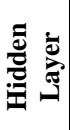 } & \multirow{2}{*}{ 苞 } & \multirow{2}{*}{$\begin{array}{l}\text { 유 } \\
\text { 흘 }\end{array}$} & \multicolumn{2}{|c|}{ Ripe } & \multicolumn{2}{|c|}{ Mature } & \multicolumn{2}{|c|}{ Raw } & \multirow{2}{*}{ 异 } \\
\hline & & & & $\mathbf{T}$ & $\mathbf{F}$ & $\mathbf{T}$ & $\mathbf{F}$ & $\mathbf{T}$ & $\mathbf{F}$ & \\
\hline 1 & 5 & 0.1 & 100 & 3 & 2 & 1 & 4 & 5 & 0 & 60 \\
\hline 2 & 5 & 0.2 & 100 & 0 & 5 & 5 & 0 & 0 & 5 & 33,33 \\
\hline 3 & 5 & 0.3 & 100 & 5 & 0 & 0 & 5 & 1 & 4 & 40 \\
\hline 4 & 5 & 0.4 & 100 & 0 & 5 & 5 & 0 & 0 & 5 & 33,33 \\
\hline 5 & 5 & 0.5 & 100 & 0 & 5 & 5 & 0 & 0 & 5 & 33,33 \\
\hline
\end{tabular}

$\mathrm{T}=$ True; $\mathrm{F}=$ False

From test 1-1 to 1-5, the highest accuracy is found in test 1-1 with learning rate 0.1 and an accuracy of $60 \%$. 


\section{G. Testing 2}

Test 2 is the same as test 1 , that is using learning rate from 0.1 to 0.5 . But there is a difference in the hidden layer. Test 1 uses 5 hidden layers, while test 2 uses 10 hidden layers. The number of an epoch is 100 and test data is 15 images.

TABLE IV. TESTING 2

\begin{tabular}{|c|c|c|c|c|c|c|c|c|c|c|}
\hline \multirow{2}{*}{$\stackrel{0}{\mathbf{z}}$} & \multirow{2}{*}{ 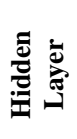 } & \multirow{2}{*}{ 苞 } & \multirow{2}{*}{ 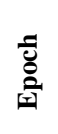 } & \multicolumn{2}{|c|}{ Ripe } & \multicolumn{2}{|c|}{ Mature } & \multicolumn{2}{|c|}{ Raw } & \multirow{2}{*}{ 窇 } \\
\hline & & & & $\mathbf{T}$ & $\mathbf{F}$ & $\mathbf{T}$ & $\mathbf{F}$ & $\mathbf{T}$ & $\mathbf{F}$ & \\
\hline 1 & 10 & 0.1 & 100 & 3 & 2 & 1 & 4 & 4 & 1 & 53,33 \\
\hline 2 & 10 & 0.2 & 100 & 3 & 2 & 2 & 3 & 4 & 1 & 60 \\
\hline 3 & 10 & 0.3 & 100 & 3 & 2 & 1 & 4 & 5 & 0 & 60 \\
\hline 4 & 10 & 0.4 & 100 & 2 & 3 & 0 & 5 & 5 & 0 & 46,67 \\
\hline 5 & 10 & 0.5 & 100 & 4 & 1 & 1 & 4 & 5 & 0 & 66,67 \\
\hline
\end{tabular}

$\mathrm{T}=$ True; $\mathrm{F}=$ False

From table 4 it can be seen that mature class is classified in ripe and raw class. This suggests that mature class is harder to classify than the ripe and raw class. Based on testing 1 and 2 with different learning rate values, it can be concluded that test 2-5 obtained the highest accuracy of $66.67 \%$. Hence, that can be used as a setting in making design classification of fruit maturity.

\section{CONCLUSION}

Classification of fruit maturity level has been done using Learning Vector Quantization. The parameters are mean, skewness, and kurtosis. Mean is average pixel value, skewness is a degree of asymmetry of colour distribution, and Kurtosis is degree of tone colour distribution in the image. Test results 1 obtained an accuracy of $60 \%$ consisting of 9 true images and 6 incorrect images with hidden layer 5 and learning rate 0,1 . Test results 2 obtained an accuracy of $66,67 \%$ consisting of 10 true images and 5 incorrect images with hidden layer 10 and learning rate 0,5 . Test image data are 15 papaya imagery consisting of 5 mature imagery, 5 imperfect images, and 5 raw images. The method could be further developed for characteristic extraction processes on a better image to reduce the error rate and improve system accuracy.

\section{ACKNOWLEDGMENT}

This research received a grant funded by IsDB (Islamic development bank). Moreover, this research come under the development of University of Sultan ageng tirtayasa center of excellence in food security for nation competitive in the field of utilization/improving added value.

\section{REFERENCES}

[1] Eliyani, Tulus, and F. Fahmi. Identification of Maya Rabo Papaya Fruit Maturity Level Using Image Processing Based on RGB Color with K-Means Clustering. Singuda ENSIKOM 1. 2013.

[2] Riyadi, S, M.M. Mustafa, A. Hussain, A. Hamzah. Papaya Fruit Grading Based on Size Using Image Analysis. Proc. International Conference on Electrical Engineering and Informatics. 2007.

[3] Sugiyanto, Sigit, F. Wibowo. Papaya Fruit Maturity Classification (Carica Papaya L) California (Callina-Ipb 9) in the Hsv Color Space and the K-Nearest Neighbors Algorithm. Proceeding of SENATEK. 2015.

[4] Syaefullah, E. Identification of Papaya level and maturity level (Carica Papaya L.) IPB I with Digital Image Processing and Neural Network Journal of Agritech Vol. 27, No. 02. 2007.

[5] Syaefullah, E. Optimization of the Storage Conditions of Papaya Fruit before Curing with Genetic Algorithms. Institut Pertanian Bogor. 2008.

[6] Syakry, S. Abdullah, Mulyadi. Color Level Content Analysis for the Determination of the Maturity Level in Papaya Callina Fruit Image. Journal of Ilmiah Elite Elektro Lhokseumawe. Vol. 4, No. 1, 2013. pp. 31-37.

[7] Rupanagudi, S.R., Ranjani B.S., P. Nagaraj, V.G. Bhat. A Cost Effective Tomato Maturiy Grading System using Image Processing for Farmers. Proceeding of IC3I. 2014.

[8] Raut, K. and V Bora. Assessment of Fruit Maturity using Digital Image Processing, International Journal of Science Technology and Engineering, Vol 3, Issue 1. 2016. pp. 273-279.

[9] Mohammadi, V., K. Keiralipour, M.G. Varnamkhasti. Detecting Maturity of Persimmon Fruit Based on Image Processing Technique. Scientia Horticulture, Vol 184. 2015. pp 123-128.

[10] Kinjo, H., N. Oshiro, S.C. Duoung. Fruit Maturity Detection Using Neural Network and Odor Sensor. Proc. The $10^{\text {th }}$ of Asian Control Conference. 2015.

[11] Sutarno and S.P Fauliah. Implementation of LVQ Algorithm for Durian Fruit Classification Using GLCM Parameters. Proc. International Conference on Science and Innovated Engineering. 2019.

[12] Simbolon, Z.K., S.A. Syakry, Mulyadi, M. Syahroni. Separation of The Mature Level of Papaya Callina Fruit Automatically Based on Color $(R G B)$ uses Digital Image Processing. Proc. International Conference on Science and Innovated Engineering. 2019. 